\title{
Integrated Yard Space Allocation and Yard Crane Deployment Problem in Resource-Limited Container Terminals
}

\author{
Caimao $\operatorname{Tan}^{1}$ and Junliang $\mathrm{He}^{2}$ \\ ${ }^{1}$ Scientific Research Academy, Shanghai Maritime University, No. 1550 Haigang Ave., Shanghai 201306, China \\ ${ }^{2}$ Engineering Research Center of Container Supply Chain Technology, Ministry of Education, \\ Shanghai Maritime University, Shanghai 201306, China \\ Correspondence should be addressed to Junliang He; soldierlianglian@163.com
}

Received 16 August 2016; Revised 12 September 2016; Accepted 19 September 2016

Academic Editor: Lu Zhen

Copyright (C) 2016 C. Tan and J. He. This is an open access article distributed under the Creative Commons Attribution License, which permits unrestricted use, distribution, and reproduction in any medium, provided the original work is properly cited.

\begin{abstract}
Yard storage space and yard crane equipment are the core resources in the container terminal yard area. This paper studies the integrated yard space allocation (outbound container space) and yard crane deployment problem in resource-limited container terminals where yard space and yard cranes are extremely scarce. Two corresponding counterstrategies are introduced, respectively, and the integrated problem is solved as mixed integer programming. The model this paper formulated considers the container volume fluctuation of the service line, and the objective is a trade-off between yard sharing space and terminal operation cost. In numerical experiments, this paper tries to reveal the management meaning in practical operation of container terminal and provides decision support for terminal managers; therefore a series of scenarios are presented to analyze the relations among the yard sharing space, the number of yard cranes, the size of yard subblock, and the cost of terminal operation.
\end{abstract}

\section{Introduction}

With the rapid development of global economy, as a center of interregional trade, international container transportation has experienced rapid growth. Container transportation has been developing for nearly 30 years and its throughput kept a sustained increase except for the world economic crisis in 2009. Global container throughput witnesses a new record: 678 million TEUs in 2014, and, according to the forecast by Drewry, it will be greater than 840 million TEUs in 2018 .

The sustained growth of the container market puts forward a higher requirement for the operation efficiency of container terminal. However, the overall berth production efficiency is not in pace with the trend of shipping maximization, according to the Drewry report in 2014. One of the main reasons is the container terminal operational bottleneck moving from the seaside to the yard area, and therefore the operational efficiency in the yard area becomes increasingly significant to the container terminals $[1,2]$.

The storage yard management is complex in practice and involves two interrelated decision problems: (1) the storage space allocation problem, which is to determine the storage locations for incoming containers, and (2) the yard crane (YC) deployment problem, which is to decide the number of YCs working in each block and their movements between blocks [3]. Generally speaking, yard space allocation considers the containers storage requirement and operating time windows of the service line, and the workload requirement of YCs is that the yard crane deployment must be involved.

Yard managers usually solve the two decision problems sequentially in such a way that space allocation is determined first and the resulting workload is used to deploy the YC accordingly. However, this planning procedure ignores considering the impact of a yard space allocation plan on the operational efficiency of YC, and this impact will be great in some case. In practice, the storage allocation plan determines the distribution of $\mathrm{YC}$ workload over the entire yard and affects YC deployment decisions. In some situations, the YC workload varies greatly between consecutive periods (working shifts) or the YC workload concentrates in certain areas (blocks or yard rows) because of inappropriate space allocation (YC deployment is not considered), and this may lead to unnecessary movement of YCs or/and even traffic congestion in the yard. Consequently, it is necessary to 
integrate these two related problems as a system, so that the yard space allocation and yard crane deployment can be properly coordinated.

Another emerging issue is that there are still many container terminals confronted with the resource-limited problem, such as Shanghai Yangshan port or Ningbo-Zhoushan port, although there are many other terminals facing a severe overcapacity situation, and the limited resources in the yard area mainly concern the yard storage resource and YC equipment resource. Take Ningbo Port Beilun Phase IV Container Terminal as an example; its throughput has reached 5 million TEUs in 2014, while the designed annual throughput is only 2 million TEUs. The yard storage space and YC equipment resources are extremely scarce; therefore the yard stacking utilization has risen to more than $90 \%$ during handling peak period, and there are only 4 fixed YCs in each row in the yard while they should be serving 6 blocks. Consequently, there is a continued need to study the optimization of yard operation, especially for the resourcelimited container terminals.

This paper aims to solve resource-limited predicament in the yard area and thereby improve the operational efficiency in the terminal. Considering that the bottleneck of container port has moved from the quay side to the yard area, the operation optimization in the yard area is regarded as the point of penetration. This paper integrated yard space allocation and yard crane deployment problem; hence an integrated model is formulated and two corresponding counterstrategies (the space sharing strategy and yard crane interzone movement strategy) are introduced. These two strategies are used to solve yard storage space resource and yard crane equipment resource scarce problem, respectively. The authors focus on the integrated yard space allocation and yard crane deployment in the tactical level, and the major contributions are provided as follows:

(1) An integrated mathematical optimization model is formulated, which provides a comprehensive view of yard space allocation and yard crane deployment problem; the objective function of the model is a trade-off between yard space utilization and yard operation cost.

(2) Two factors impacting the operational efficiency of storage yard are introduced, and these factors play a significant role in the practical container terminal operation but have seldom been presented in existing literatures. Meanwhile, the container volume fluctuation of the service line is also under consideration.

(3) A detailed scenario analysis among the yard sharing space, the number of YCs, the size of yard subblock, and the operation cost of container terminal is presented, which can provide a precise relative reference to container terminal manager.

The remainder of this paper is organized as follows. Section 2 reviews the related researches. Section 3 elaborates the description for the yard space allocation problem and yard crane deployment problem as well as a mathematical model formulation in Section 4. Numerical examples are given in Section 5, and a brief conclusion remark is presented in the concluding section.

\section{Literature Review}

Container terminal operation management is an extremely complex conundrum because too many elements are involved in the system. Up to the present, there are numerous studies on the container port operations [4-6], such as quay crane allocation and inner truck routing in the seaside, yard space allocation, and yard crane scheduling in the landside. For a comprehensive overview, we refer readers to the review works given by Vis and De Koster [7], Steenken et al. [8], and Stahlbock and Voß [9]. In this section, a brief review of studies highly related to container terminal operation in the yard area is provided.

2.1. Yard Space Allocation. Generally speaking, storage space allocation can be analyzed at various levels according to the storage space unit considered: yard section, yard block, yard subblock, yard bay, and individual slot [3]. This paper follows up the space sharing strategy [10] between neighbor storage units based on yard template generation; therefore the papers considering yard space allocation in subblock level will be introduced minutely in this subsection.

Lee et al. [11] used the consignment strategy to store incoming export and transshipment containers at dedicated locations according to the destination vessel, helping to reduce the reshuffling level to a negligible level; this strategy has initiated a new line of yard space allocation problem. Han et al. [12] extended their research to optimize the yard template and the yard storage allocation problem simultaneously; the yard storage space is reserved for each specific vessel in this paper. Jiang et al. [10] put forwarded the concept of space sharing strategy between neighbor subblocks, so the container yard can improve land utilization based on this creative and meaningful concept; a two-space sharing method was also proposed to improve the space utilization of a certain yard template. Jiang et al. [13] considered a flexible space sharing strategy compared with the previous fixed space sharing pattern. A yard template determined the allocation of spaces in the container terminal yard, while fluctuation of demand for freight transportation brings challenge to yard template generation. Zhen [14] proposed a yard template planning considering random numbers of containers that will be loaded onto vessels that visit the port periodically. Similar to Han et al. [12], the traffic congestions problem in the yard area is also considered. However, there are still some important factors which have received inadequate attention but should not be overlooked in practical terminal yard space management. Part of those factors is the proportional matching of quay operation queue and YC loading point of the service line.

2.2. Yard Crane Deployment. With the yard space allocation plan determined, the information of grounding and retrieval activities in all blocks can be available for planning the yard crane deployment [3]. Compared with yard crane scheduling 
problem, the yard crane deployment emphasizes the macro configure level. Zhang et al. [15] addressed crane deployment problem with the workload of each block in each period was given, and try to find the optimal times and routes of yard crane movements among yard blocks so that the total delayed workload in the yard is minimum. With the same objective, Chung et al. [16] and Linn et al. [17] formulated yard crane deployment problem as a mixed integer linear program; they loosen the restrictions in Zhang et al. [15] that each block should include not more than two cranes, and the maximum number of transfers in or out of a block is limited. In the above-mentioned researches, the type of the yard crane is a single E-RTG (electric yard crane) system. Cao et al. [18] focused on the deployment problem of double-rail-mounted gantry yard crane system which has been applied in Western Automated Container Terminals. An integer programming model was formulated as well as a greedy heuristic algorithm; a simulated annealing algorithm and a combined yard crane scheduling heuristic were designed to solve the proposed problem.

2.3. Integrated Management. The integration of the yard space allocation and yard crane deployment problem is also regarded by many researchers $[10-12,19-21]$ due to the relationships between these two problems. K. H. Kim and H. B. Kim [19] discussed a method to determine the optimal amount of storage space and the optimal number of transfer YCs for handling import containers. The cost model consists of the space cost, the investment cost of transfer cranes, and the operating cost of transfer cranes and trucks. However, this model cannot give a detailed storage location for containers or group of containers. Lee et al. [11], Han et al. [12], and Jiang et al. [10] considered yard space allocation and relevant workload assignment problem, and the yard crane resource requirement was also included, yet the yard crane interblock movement is not allowed. Lee et al. [20] addressed the integrated problem for bay allocation and yard crane scheduling in transshipment container terminal and allocated bay resource to fleet containers in a more efficient way. Receiving operation and retrieving operation in the storage yards were considered simultaneously to achieve a more efficient operation of the yard crane, while bay allocation focused on a block vision rather than yard overall prospect. Won et al. [21] proposed an integrated decision-making framework for the yard planning that simultaneously considers storage space, yard crane, and traffic area in the container terminal.

The integrated yard space allocation and yard crane deployment problem studied in this paper follows up the work of Jin et al. [3]. Instead of dealing with detailed daily subblock space allocation and yard crane deployment problem at the operational level, this paper addresses the tactical planning level. In addition, the subject of this study is these container terminals where yard space and yard crane resources are extremely limited; the yard space sharing strategy and yard crane interzone movement strategy are applied consequently. Different from Jin et al. [3], this paper simultaneously considers the space allocation and yard crane deployment in the yard area, and not only the operation cost, but also the yard storage space utilization is considered.

\section{Problem Description}

Before we elaborate the yard space allocation and yard crane deployment problem, there are some concepts existing in the text that must be explained.

(i) Service Line. The service line is service object of the container terminal; in a sense, a service liner is a set of many voyages with the same departure and destination. Different from Line, the line is a general concept, while the service line is a specific concept, and the object is the container terminal.

(ii) Quay Operation Queue. The quay operation queue is the number of quays that service a specified service line (loading and unloading operation) simultaneously. The quay operation queue of a service line is usually determined by the vessel size, container volumes (loading and unloading operation), and the service line priority level. Generally speaking, the higher the priority level of service line, the greater the number of quay operation queues that the service line has.

(iii) YC Loading Point. The YC loading point is the number of YCs servicing a certain service line (loading operation) simultaneously. Because of the different operation efficiency of quay and yard crane, there is a proper matching proportion between the quay operation queue and $Y C$ loading point for a service line, and it is optimal matching that 1 quay operation queue deploys 2 or 3 YC loading points.

Remarkably, for a service line, there is at most one $Y C$ loading point in one block even if it has two or more subblocks assigned in one block because of the limitation of YCs. As showed in Figure 1, there are two service lines: service line 1 uses vessel A with 800 TEUs outbound containers and service line 2 uses vessel B with 3000 TEUs outbound containers. Both service lines have deployed 4 quay operation queues. As we can see, service line 1 only has 800 TEUs outbound containers to be loaded (about 6 subblocks volumes), but because line 1 deployed 4 quay operation queues, 8 yard $Y C$ loading points are needed at least, so 8 subblocks located in 8 different blocks are assigned to line 1 consequently. Meanwhile, although service line 2 has 3000 TEUs (20 subblocks volumes), it only deployed 4 quay operation queues, 12 yard YC loading points could be fulfilled at most, and 20 subblocks concentrated which are located in 12 blocks are assigned to service line 2 accordingly.

3.1. Storage Space Allocation. The storage space allocation determines the container yard stacking position in the subblock for each service line of the terminal. The allocation plan will normally not change once it is determined since vast shipping companies service lines are relatively stable. However, there has been a realistic problem that it is difficult to calculate the accurate subblocks that each service line should be assigned because of the uncertainty of maritime market. Therefore the volume of outbound containers fluctuates frequently. If the yard storage space (subblocks) is 


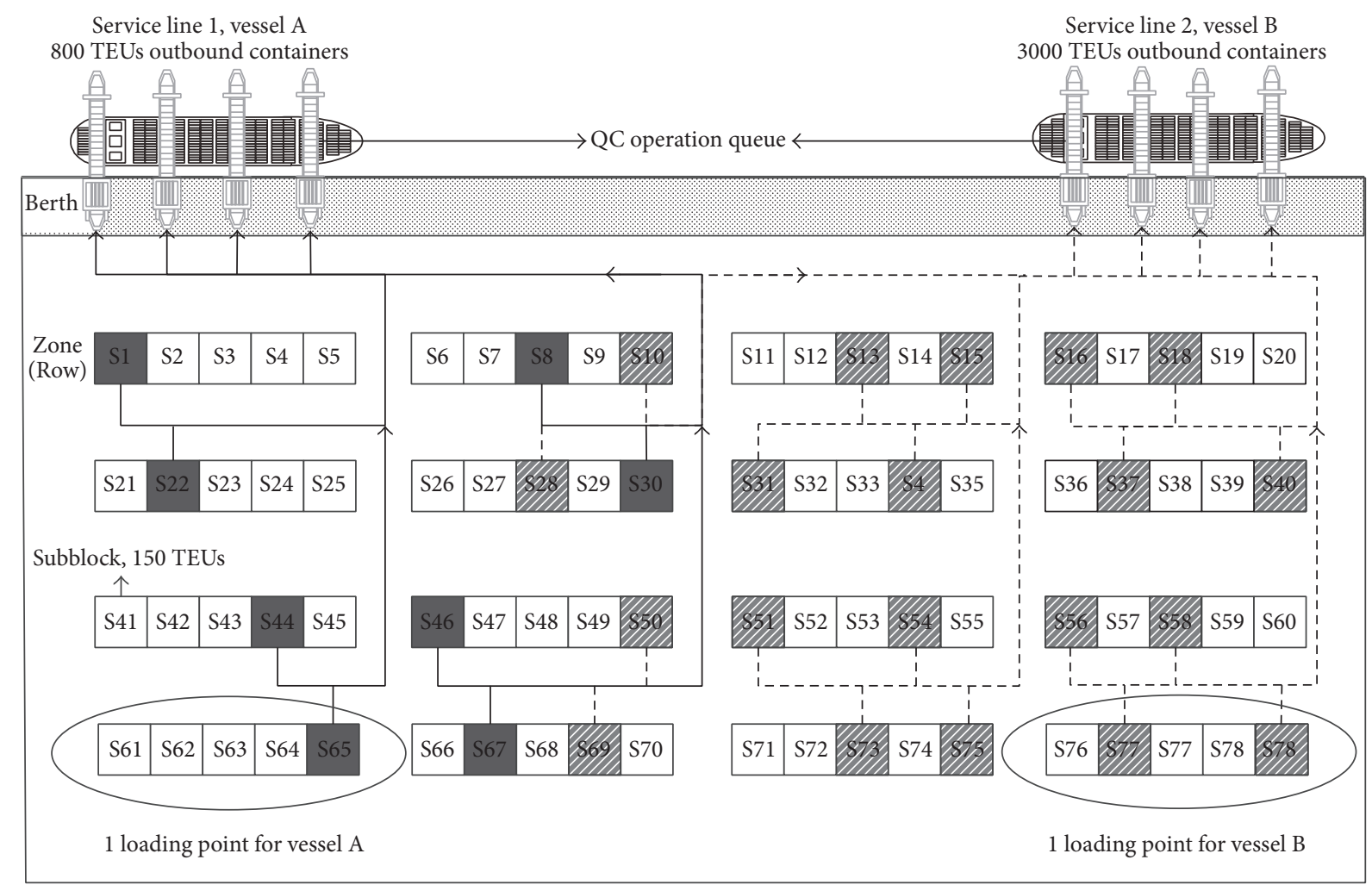

FIGURE 1: A typical yard space configuration of container terminal.

assigned according to the service line minimal demand, it is likely to face storage space shortage for a busy voyage. On the contrary, the terminal yard space will not be sufficient.

For the container terminal with a static yard template $[11,12]$, all the subblocks in each block have a fixed space capacity, which means each service line needs to be assigned a large enough yard storage space to satisfy containers stacking demand at the peak time. To take advantage of the benefit of consignment strategy and increase the yard storage space utilization, Jiang et al. [10] proposed a space sharing strategy which allows some certain space to be shared between neighbor subblocks. For a detailed sharing space strategy description, we refer readers to the work given by Jiang et al. [10].

In general, for a resource-limited container terminal, the main concern is the utilization of yard storage in the process of yard space allocation. Accordingly, the objective could be concentrated on the total sharing space between yard neighbor subblocks. Constraints that should be considered when allocating storage space mainly include the following:

(i) The storage capacity allocated to each service line should be sufficient, so that it could meet the stacking demand.

(ii) For each service line, in order to achieve a high operational efficiency as far as possible, the proportion of quay operation queue and $\mathrm{YC}$ loading point would be in the reasonable range. (iii) The YC loading point in the block must be well controlled at any time period; otherwise traffic congestion can be expected.

3.2. Yard Crane Deployment. The yard crane deployment problem is to designate and schedule YCs route according to the workload requirement in the yard area. Many relevant researches usually focus on the deployment problem between yard blocks in the same zone that only the yard crane intrazone movement is considered. This is a commendable strategy when the terminal yard crane resources are adequate.

However, there may be a situation that only four YCs are in one zone with 5 or 6 blocks in some container terminals. In this case, 4 YCs should service 5 or 6 blocks; the YCs have to move among different block zones. Therefore, the yard crane interzone movement is enabled in this terminal to satisfy operational requirements. In this study, we concentrated on the yard crane interzone movement rather than the intrazone movement, because the former operation time cost and fuel consumption cost are much higher than the latter. Figure 2 shows a diagram of E-RTG interzone movement process. For a detailed yard crane movement patterns description, we refer readers to the works given by Linn et al. [17] and Zhang et al. [15].

For yard crane deployment, the objective is to optimize workload distribution of each yard row during all the periods. Therefore, the optimization objective in this paper is to minimize YCs operation cost when deploying yard crane. Constraint that should be considered is to ensure the number 


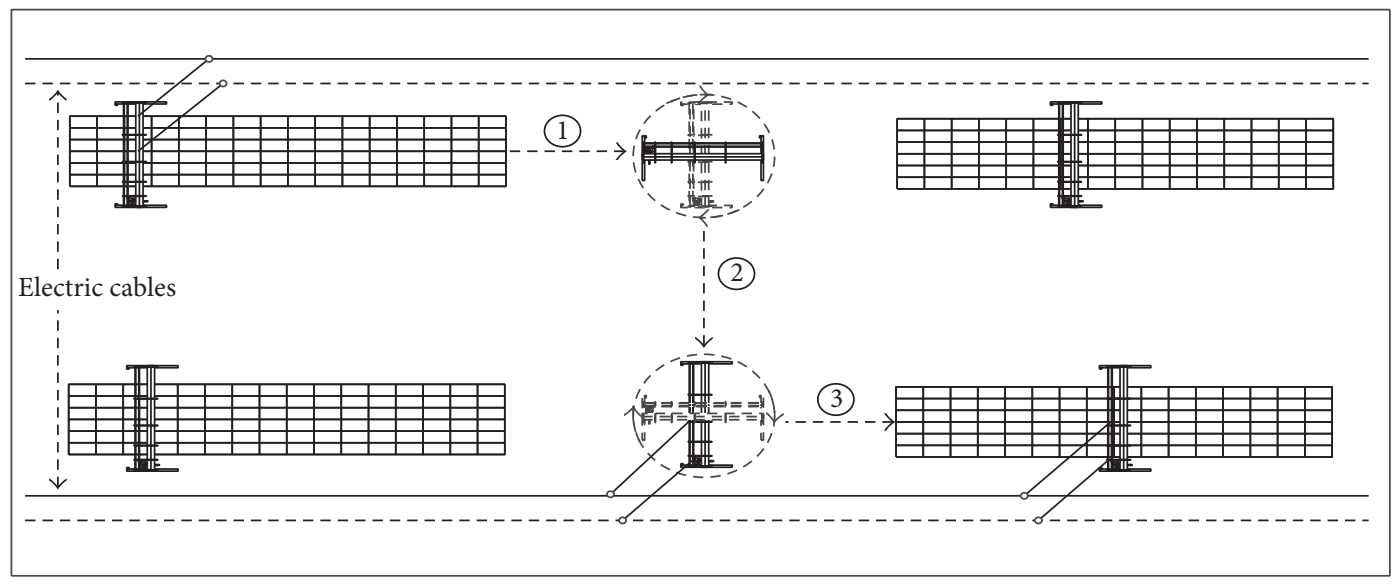

FiguRE 2: E-RTG interzone movement process.

of YCs deployed in each row can satisfy the container handling requirement.

\section{Mathematic Model}

In this section, the integrated yard space allocation and yard crane deployment mathematical model for resource-limited container terminal is formulated. The authors raised the main characteristics of resource-limited container terminal storage space allocation and yard crane deployment problem and then presented the relevant counterstrategies accordingly. For yard space strained problem, the space sharing strategy is applied which has been proposed by Jiang et al. [10], and as for yard crane equipment shortage, the yard crane interzone movement is enabled.

4.1. Assumptions. The following assumptions are made in the integrated model:

(1) The yard storage space can satisfy the minimum service line outbound containers stacking demand, and the YCs are sufficient to guarantee the basic handling requirement.

(2) The service lines berthing position are given and fixed; hence once the service line containers are assigned to the subblocks, the minimal inner truck transportation distances are determined.

(3) A subblock can be reserved for only one service line, except for part of the storage space which may be shared with its neighbor assigned service lines and will not change once the storage plan is determined.

(4) The YC can only shift to one yard zone in one period; it means that once the yard crane moved from one zone to another, then it should be staying in the zone before the next planning period is begun.

4.2. Mathematic Formulation. This model aims to deal with the yard space allocation problem and yard crane deployment problem at the tactical level and provides the following results: (1) yard storage space allocation plan for outbound containers of all the service lines, which considers the container volumes, quay operation queues, YC loading points, and handling conflicts of service lines in the storage yard; (2) yard crane deployment profile, including the yard crane assignment plan in the initial period and subsequent yard crane moving scheme.

Sets

$T:$ set of time periods, $T=\{1,2, \ldots, N T\}$

$B$ : set of yard blocks, $B=\{1,2, \ldots, N B\}$

$S$ : set of yard subblocks, $S=\{1,2, \ldots, N S\}$

$S_{i}^{n}$ : set of neighbor subblocks of subblock $i \in S, S_{i}^{n} \in S$

$S_{q}^{s}$ : set of subblocks belonging to block $q \in B, S_{q}^{s} \in S$

$R$ : set of yard rows (zone) in the terminal yard, $R=$ $\{1,2, \ldots, N R\}$

$B_{r}$ : set of blocks belonging to row $r \in R, B_{r} \in B$

$L:$ set of service lines of terminal, $L=\{1,2, \ldots, N L\}$

$Y$ : set of YCs, $Y=\{1,2, \ldots, N Y\}$

Parameters

$c_{m}^{\mathrm{min}}$ : minimal outbound containers of service line $m \in L$ (TEUs)

$c_{m}^{\max }$ : maximal outbound containers of service line $m \in L$ (TEUs)

$p_{m}:$ quay operation queues of service line $m \in L$

$\mu^{\min }$ : minimal YC loading points that one quay operation queue demands

$\mu^{\max }$ : maximal YC loading points that one quay operation queue can satisfy

$t_{m}^{s}$ : time period to start handling of service line $m \in L$

$t_{m}^{e}$ : time period to end handling of service line $m \in L$

$h_{m t}$ : handling parameter of service line $m \in L$, equal to 1 if $t \in\left[t_{m}^{s}, t_{m}^{e}\right]$, otherwise equal to 0 
$v^{s}$ : maximal space capacity of each subblock (TEUs)

$v^{b}$ : maximal space capacity of each yard block (TEUs)

$\delta^{b}$ : maximal YCs enabled operating in one yard block

$\delta^{r}$ : maximal YCs enabled operating in one block row

$\omega_{m n}$ : yard space sharing space when subblocks of service line $m \in L$ and service line $n \in L$ are neighbored (in this paper, $\omega_{m n} \in\{0,1\}$; it is usually determined by the container buildup pattern of two service lines [14])

$\theta$ : fixed capacity of one sharing space (TEUs)

$d_{i m}^{t}$ : inner truck moving distance (loading and unloading) if service line $m \in L$ is assigned to subblock $i \in S(\mathrm{~km})$

$d_{r r^{\prime}}^{c}$ : yard crane movement distance between row $r \in R$ and row $r^{\prime} \in R(\mathrm{~km})$

$\varphi$ : inner truck transportation cost (¥/km/TEU)

$\sigma$ : fixed time consumption of yard crane interzone movement (h)

$\pi$ : yard crane time cost $(¥ / \mathrm{h})$

$\rho$ : yard crane movement cost $(¥ / \mathrm{m})$

$\lambda_{r r^{\prime}}$ : yard crane interzone movement cost between row $r \in$ $R$ and row $r^{\prime} \in R, r \neq r^{\prime}(¥)$, where $\lambda_{r r^{\prime}}=\sigma \pi+d_{r r^{\prime}}^{c} \rho$, if $r=r^{\prime}, \lambda_{r r^{\prime}}=0$

$\varepsilon$ : a small and positive constant

\section{Decision Variables}

$x_{i m} \in\{0,1\}: 1$, if subblock $i \in S$ was assigned to service line $m \in L ; 0$, otherwise

$y_{r r^{\prime} t} \in N$ : YCs moving from row $r \in R$ to row $r^{\prime} \in R$ at the end of time period $t \in T$ (and $y_{s r 0}$ is initial YCs of row $r \in R$ in the beginning of the period)

$z_{m q} \in\{0,1\}$ : the number of YC loading points of service line $m \in L$ in block $q \in B$

$w_{r t}^{d} \in N$ : minimal yard crane requirement of row $r \in$ $R$ in time period $t \in T$

$w_{r t}^{a} \in N$ : the number of YCs assigned to row $r \in R$ in time period $t \in T$

\section{Objective Function}

$$
\begin{aligned}
\operatorname{maximize} f_{1} & =\sum_{i \in S} \sum_{j \in S_{i}^{n}} \sum_{m, n \in L} x_{i m} x_{j n} \omega_{m n} \theta ; \\
\operatorname{minimize} & f_{2}=f_{2}^{t}+f_{2}^{c} ; \\
f_{2}^{t} & =\sum_{i \in s} \sum_{m \in L} x_{i m} d_{i m}^{t} \varphi v^{s} ; \\
f_{2}^{c} & =\sum_{r \in R} \sum_{r^{\prime} \in R} \sum_{t \in T} y_{r r^{\prime} t} \lambda_{r r^{\prime}} .
\end{aligned}
$$

The mathematical model proposed in this section is a multiobjective optimal model; hence the authors transferred it into a single-objective problem by the method of weighted allocation. Define $\alpha$ as the coefficient of yard storage space in the process of terminal operation management and use coefficient $\alpha$ to combine the two objectives. Furthermore, because the dimensions of two objectives are different, thus nondimensional processing is needed. Note that $f_{1}^{\max }$ and $f_{1}^{\text {min }}$ are the independent maximal and minimal value of $f_{1}$, respectively; $f_{2}^{\max }$ and $f_{2}^{\min }$ are the independent maximal and minimal value of $f_{2}$. Therefore, the integrated objective function can be expressed as follows:

$$
\max f=\frac{\alpha\left(f_{1}-f_{1}^{\min }\right)}{\left(f_{1}^{\max }-f_{1}^{\min }\right)}+\frac{(1-\alpha)\left(f_{2}^{\max }-f_{2}\right)}{\left(f_{2}^{\max }-f_{2}^{\min }\right)} .
$$

In formula (5), the coefficient $\alpha$ could be set as $0,0.1, \ldots, 1.0$ with a step size of 0.1 . This step could be adjusted manually according to problem size and terminal operator's preference. By changing the value of $\alpha$, different sets of solutions can be obtained. In other words, when $\alpha$ is smaller, the solutions are more space-utilizing. On the contrary, with the increase of $\alpha$, the solutions are more costsaving.

\section{Constraints}

$$
\begin{aligned}
\sum_{m \in L} x_{i m} & \leq 1 \quad \forall i \in S \\
\sum_{i \in s} x_{i m} & \geq\left\lceil\frac{c_{m}^{\min }}{v^{s}}\right\rceil \quad \forall m \in L \\
\sum_{i \in s} x_{i m} & \leq\left\lceil\frac{c_{m}^{\max }}{v^{s}}\right\rceil \quad \forall m \in L \\
\sum_{i \in S} \sum_{m \in L} x_{i m} & =N S \\
z_{m q} & \leq \sum_{i \in S_{q}^{s}} x_{i m}
\end{aligned}
$$$$
\forall m \in L, q \in B
$$$$
z_{m q} \geq \sum_{i \in S_{q}^{s}} x_{i m} \varepsilon
$$

$\forall m \in L, q \in B$

$$
\begin{gathered}
\sum_{q \in B} z_{m q} \geq \mu^{\min } p_{m} \quad \forall m \in L \\
\sum_{q \in B} z_{m q} \leq \mu^{\max } p_{m} \quad \forall m \in L \\
\left\lceil\frac{c_{m}^{\max }}{v^{s}}\right\rceil \geq \mu^{\min } p_{m} \quad \forall m \in L \\
\sum_{m \in L} z_{m q} h_{m t} \leq \delta^{b} \quad \forall q \in B, t \in T \\
w_{r t}^{d}=\sum_{m \in L} \sum_{q \in B_{r}} z_{m q} h_{m t}
\end{gathered}
$$




$$
\begin{aligned}
& w_{r t}^{d} \leq \delta^{b} \quad \forall r \in R, t \in T \\
& \sum_{m \in L} x_{i m} h_{m t}+\varepsilon \sum_{j \in S_{i}^{n}} \sum_{m \in L} x_{j m} h_{m t} \leq 1 \quad \forall i \in S, t \in T \\
& \sum_{r \in R} y_{s r 0}=N Y \\
& \sum_{r^{\prime} \in R} y_{r r^{\prime} t}=y_{s r 0} \quad \forall r \in R, t=1 \\
& \sum_{r^{\prime} \in R} y_{r r^{\prime} t}=\sum_{r^{\prime} \in R} y_{r^{\prime} r(t-1)} \\
& \forall r \in R, 2 \leq t \leq N T-1 \\
& y_{s r 0}=\sum_{r^{\prime} \in R} y_{r^{\prime} r t} \\
& \forall r \in R, t=N T \\
& w_{r t}^{a}=y_{s r 0} \quad \forall r \in R, t=1 \\
& w_{r t}^{a}=\sum_{r^{\prime} \in R} y_{r^{\prime} r(t-1)} \\
& \forall r \in R, t \in T, t \neq 1 \\
& w_{r t}^{a} \geq w_{r t}^{d} \quad \forall r \in R, t \in T \\
& w_{r t}^{a} \leq \delta^{r} \quad \forall r \in R, t \in T \\
& x_{i m} \in\{0,1\} \quad \forall i \in S, m \in L \\
& y_{s r 0} \in N \quad \forall r \in R \\
& y_{r r^{\prime} t} \in N \\
& \forall r, r^{\prime} \in R, t \in T \\
& z_{q m} \in\{0,1\} \\
& \forall m \in L, q \in B \\
& w_{r t}^{a}, w_{r t}^{d} \in N \quad \forall r \in R, t \in T .
\end{aligned}
$$

The constraints of the mathematical model are composed of three parts: the yard space allocation constraints, the yard crane deployment constraints, and the variables range constraints.

Equations (6) to (18) are the constraints of the first part, which defines the rules of yard space allocation. Equation (6) states that each subblock should be reserved for at most one service line during the entire planning horizon. Equations (7) and (8) state that the subblocks assigned to the service line must satisfy the outbound containers storage demand of the service line. Considering the service line outbound container volumes are not generally fixed and the yard storage space is extremely limited, the loosened constraints are presented. Equation (9) ensures that all the subblocks should be assigned to a service line. Equations (10) and (11) are the calculation equations of service line YC loading points in a block, equal to 1 if there is at least one subblock reserved for the service line, but otherwise equal to 0 . Equations (12) to (14) state the relationship between the service line quay operation queue in the seaside and the YC loading point in the yard area. Equation (15) ensures the maximal handling YCs in the block. Equations (16) and (17) restrict the maximal handling YCs in the yard row. Equation (18) states that when one of the subblocks is in loading state, the other neighbor subblocks are unavailable for service line that should be handled at the same time.

Equations (19) to (26) are the constraints of the second part, which defines the rules of yard crane deployment. Equation (19) guarantees that the summation of initial YCs deployment in each row is equal to the number of YCs. Equations (20) to (22) ensure the YCs resource flow balance in the process of YCs interzone movement in each period of planning horizon. Equations (23) and (24) are the calculation equations of YCs in each yard row. Equations (25) and (26) ensure that the YCs operating in the row should satisfy the operational demand and not exceed the maximal YCs bound in the row at the same time.

Finally, the domains of variables defined by (27) to (31) are the constraints of the third part.

Linear Transformation. As formula (1) is a nonlinear function, a linear transformation operation is applied. After linear transformation, formula (1) is equal to

$$
\begin{aligned}
& \max \quad f_{1}=\sum_{i \in S} \sum_{j \in S_{i}^{n}} \sum_{m, n \in L} \phi_{i j m n} \omega_{m n} \theta \\
& \phi_{i j m n} \leq x_{i m} \quad \forall i \in S, j \in S_{i}^{n}, m, n \in L \\
& \phi_{i j m n} \leq x_{j n} \quad \forall i \in S, j \in S_{i}^{n}, m, n \in L \\
& \phi_{i j m n} \geq x_{i m}+x_{j n}-1 \\
& \quad \forall i \in S, \quad j \in S_{i}^{n}, m, n \in L \\
& \phi_{i j m n} \in\{0,1\} \quad \forall i \in S, j \in S_{i}^{n}, m, n \in L .
\end{aligned}
$$

\section{Numerical Experiment}

To evaluate the effectiveness of the proposed model, a series of experiments with different scales are conducted. Section 5.1 introduces the parameters used for generating the experiments. Section 5.2 analyzes the trade-off between yard storage space resource utilization and yard operation cost. Section 5.3 researches the effects of YCs on yard storage space and operational cost. Section 5.4 explores the influence of subblock volume on the yard management. The integrated model in this paper is solved by ILOG CPLEX 12.4, and all of the computation experiments are conducted on a workstation with Inter Xeon CPU with $64 \mathrm{GHz}$ RAM.

5.1. Instances. At present, many of the container line arrival patterns are weekly arrival. In other words, the voyage of service line arrives at the terminal once a week. Therefore, the planning horizon of this experiment is 1 week, and each day is split into 3 periods of 8 hours in consideration of practical working shift in the container terminal. The experiment in 
TABLE 1: Configuration parameters of container terminal yard.

\begin{tabular}{lccccc}
\hline Class & $\begin{array}{c}N L \\
\text { (periods) }\end{array}$ & $\begin{array}{c}\text { NB } \\
\text { (blocks) }\end{array}$ & $\begin{array}{c}\text { NS } \\
\text { (subblocks) }\end{array}$ & $\begin{array}{c}\text { NR } \\
\text { (rows) }\end{array}$ & $\begin{array}{c}\text { NY } \\
\text { (YCs) }\end{array}$ \\
\hline Class S & 6 & 8 & 32 & 2 & 6 \\
Class M & 8 & 16 & 64 & 4 & 12 \\
Class L & 10 & 24 & 96 & 6 & 18 \\
\hline
\end{tabular}

TABLE 2: Configuration parameters of yard crane and intertruck.

\begin{tabular}{lcccccccc}
\hline Parameters & $\mu^{\min }$ & $\mu^{\max }$ & $\delta^{b}$ & $\delta^{r}$ & $\varphi$ & $\rho$ & $\sigma$ & $\pi$ \\
\hline Value & 2 & 3 & 2 & 6 & 15 & 2.4 & 0.5 & 200 \\
\hline
\end{tabular}

this paper considers three different storage yard scales (small, medium, and large); more precisely, the instances with 6 to 10 service lines, 6 to $18 \mathrm{YCs}$, and 8 to 24 blocks, resulting in classes $6 \times 8 \times 6$ (class S), $8 \times 16 \times 12($ class $M)$, and $10 \times 24 \times$ 18 (class L), are tested (Table 1 ).

For all the classes, the authors assume that the capacity of each block is 800 TEUs, and the subblock capacity $\left(v^{b}\right)$ is 200 TEUs. Meanwhile, the maximal sharing space capacity of each subblock is equal to 20 TEUs $\left(10 \% v^{b}\right)$. The yard crane handling parameters and intertruck transportation parameters are shown in Table 2.

For each class, three scenarios of service line loading requirement are tested, denoted by $\mathrm{W} 1, \mathrm{~W} 2$, and $\mathrm{W} 3$. The loading requirement is determined by the service line quay operation queues (input data $p_{m} \in N$, which are generated with discrete uniform distributions DU[2,3], DU[3,4], and DU $[4,5]$, resp.); the name of the instance indicates the level of the loading requirement: low requirement (W1), general requirement (W2), and high requirement (W3).

5.2. Yard Space Resource Analysis. Based on space sharing strategy, the yard storage space utilization is increased owing to the sharing storage space between neighbor subblocks. As showed in Table 3, the optimal yard operation cost equal to $99990 ¥$ and 800 TEUs' extra storage space (sharing space) are created ( $a=0$, cost-saving pattern) if space sharing strategy is applied in the yard. Obviously, this strategy can relieve terminal yard space scarce situation to a certain extent.

Meanwhile, when coefficient $a$ takes 1, it means that this model considers yard space allocation problem (spaceutilizing pattern) firstly and then the yard crane deployment problem (cost-saving pattern); it is the nonintegrated pattern in this situation. Accordingly, with the value of $a$ decreasing, the yard crane deployment is integrated with the yard space allocation problem gradually.

Furthermore, Figures 3, 4, 5, and 6 show the relationships between yard storage space and yard operation cost of different instances scales. As we can see, with the increasing of coefficient $a$, the yard sharing space increased synchronously as well as the yard operation cost. Hence, there is no ultimate solution with the maximum space sharing and the minimum operation cost. Which one should be chosen from these nondominated solutions is determined by the terminal operators according to the terminal reality. If

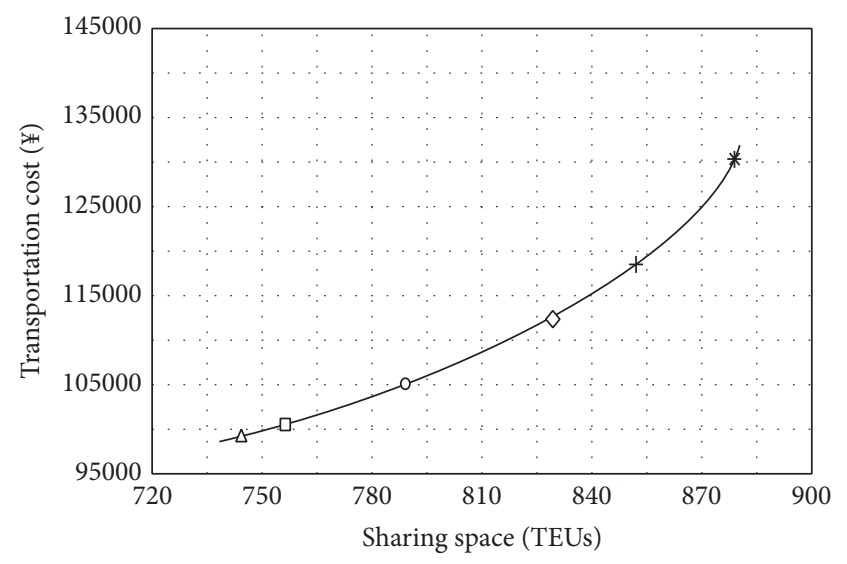

$$
\begin{aligned}
& \neg-a=0 \quad \checkmark-a=0.6 \\
& \neg-a=0.2 \quad+a=0.8 \\
& \text { - }-a=0.4 \quad \text { * } a=1
\end{aligned}
$$

FIGURE 3: Relationships between yard space and operation cost of small-scale experiments.

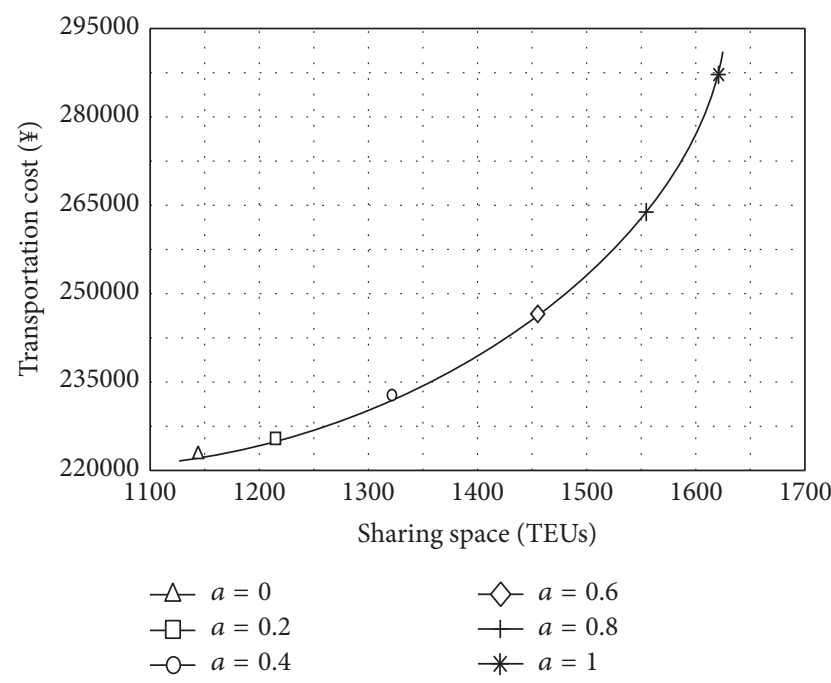

FIGURE 4: Relationships between yard space and operation cost of medium-scale experiments.

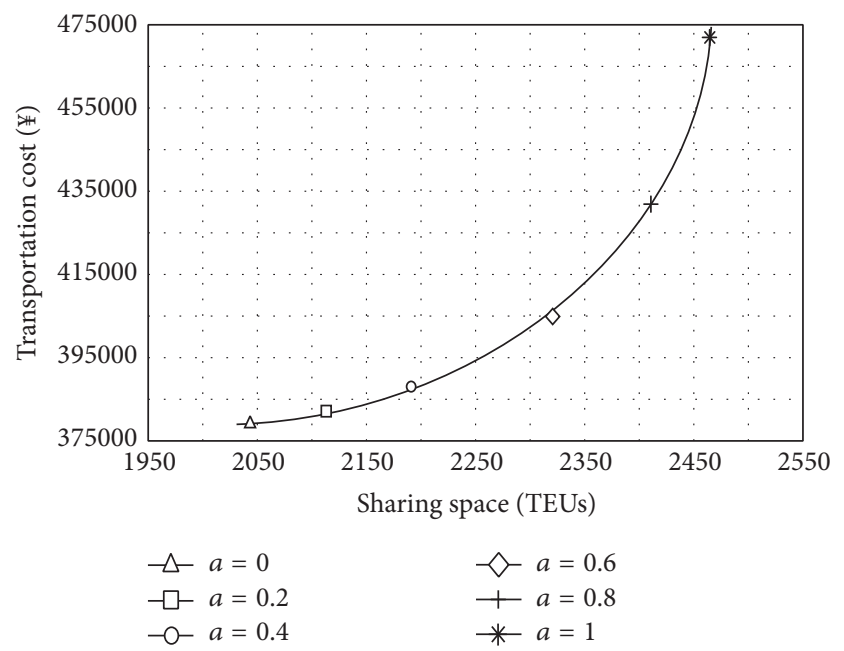

FIgURE 5: Relationships between yard space and operation cost of large-scale experiments. 
TABLE 3: Results of instances with different coefficient values.

\begin{tabular}{|c|c|c|c|c|c|c|c|c|c|c|c|c|}
\hline \multirow[b]{2}{*}{ Instances } & \multicolumn{2}{|c|}{$a=1$} & \multicolumn{2}{|c|}{$a=0.8$} & \multicolumn{2}{|c|}{$a=0.6$} & \multicolumn{2}{|c|}{$a=0.4$} & \multicolumn{2}{|c|}{$a=0.2$} & \multicolumn{2}{|c|}{$a=0$} \\
\hline & $\begin{array}{c}f 1 \\
\text { (TEUs) }\end{array}$ & $\begin{array}{l}f 2 \\
(¥)\end{array}$ & $\begin{array}{c}f 1 \\
\text { (TEUs) }\end{array}$ & $\begin{array}{l}f 2 \\
(¥)\end{array}$ & $\begin{array}{c}f 1 \\
\text { (TEUs) }\end{array}$ & $\begin{array}{l}f 2 \\
(¥)\end{array}$ & $\begin{array}{c}f 1 \\
\text { (TEUs) }\end{array}$ & $\begin{array}{l}f 2 \\
(¥)\end{array}$ & $\begin{array}{c}f 1 \\
\text { (TEUs) }\end{array}$ & $\begin{array}{l}f 2 \\
(¥)\end{array}$ & $\begin{array}{c}f 1 \\
\text { (TEUs) }\end{array}$ & $\begin{array}{l}f 2 \\
(¥)\end{array}$ \\
\hline S_W1 & 880 & 128800 & 880 & 110880 & 840 & 108900 & 800 & 103820 & 800 & 99990 & 800 & 99990 \\
\hline S_W2 & 880 & 129380 & 840 & 119960 & 840 & 110880 & 800 & 107910 & 760 & 102960 & 760 & 99990 \\
\hline S_W3 & 880 & 133340 & 840 & 127640 & 800 & 118800 & 760 & 108900 & 720 & 102960 & 680 & 99990 \\
\hline M_W1 & 1680 & 293150 & 1600 & 268500 & 1480 & 241600 & 1360 & 228830 & 1240 & 222450 & 1160 & 221760 \\
\hline M_W2 & 1600 & 286480 & 1560 & 261460 & 1440 & 239900 & 1320 & 228670 & 1240 & 224960 & 1160 & 221950 \\
\hline M_W3 & 1560 & 282360 & 1520 & 264300 & 1440 & 241860 & 1320 & 230100 & 1200 & 225960 & 1120 & 222140 \\
\hline L_W1 & 2480 & 468460 & 2400 & 432570 & 2360 & 403120 & 2200 & 387550 & 2120 & 380350 & 2080 & 376180 \\
\hline L_W2 & 2480 & 467820 & 2400 & 432800 & 2320 & 405670 & 2160 & 387610 & 2120 & 380640 & 2040 & 377050 \\
\hline L_W3 & 2400 & 468680 & 2360 & 433130 & 2280 & 405880 & 2160 & 388060 & 2080 & 381020 & 2000 & 378120 \\
\hline
\end{tabular}

TABLE 4: Results of instances with different YCs.

\begin{tabular}{|c|c|c|c|c|c|c|c|c|c|c|}
\hline \multirow[b]{2}{*}{ Instances } & \multicolumn{2}{|c|}{$N Y / N R=3$} & \multicolumn{2}{|c|}{$N Y / N R=3.5$} & \multicolumn{2}{|c|}{$N Y / N R=4$} & \multicolumn{2}{|c|}{$N Y / N R=4.5$} & \multicolumn{2}{|c|}{$N Y / N R=5$} \\
\hline & $\begin{array}{c}f 1 \\
\text { (TEUs) }\end{array}$ & $\begin{array}{l}f 2 \\
(¥)\end{array}$ & $\begin{array}{c}f 1 \\
\text { (TEUs) }\end{array}$ & $\begin{array}{l}f 2 \\
(¥)\end{array}$ & $\begin{array}{c}f 1 \\
\text { (TEUs) }\end{array}$ & $\begin{array}{l}f 2 \\
(¥)\end{array}$ & $\begin{array}{c}f 1 \\
\text { (TEUs) }\end{array}$ & $\begin{array}{l}f 2 \\
(¥)\end{array}$ & $\begin{array}{c}f 1 \\
\text { (TEUs) }\end{array}$ & $\begin{array}{l}f 2 \\
(¥)\end{array}$ \\
\hline S1_W1 & 960 & 99990 & 980 & 98040 & 980 & 97160 & 1000 & 96500 & 1000 & 96320 \\
\hline S1_W2 & 960 & 99990 & 960 & 98630 & 980 & 97640 & 980 & 96500 & 1000 & 96320 \\
\hline S1_W3 & 960 & 99990 & 960 & 99160 & 980 & 98420 & 980 & 97930 & 1000 & 96950 \\
\hline M1_W1 & 1680 & 221760 & 1700 & 217730 & 1780 & 214200 & 1820 & 211770 & 1820 & 210040 \\
\hline M1_W2 & 1600 & 221950 & 1640 & 218780 & 1700 & 215980 & 1760 & 213530 & 1760 & 211690 \\
\hline M1_W3 & 1580 & 222140 & 1620 & 219420 & 1680 & 216560 & 1700 & 213840 & 1760 & 211870 \\
\hline L1_W1 & 2480 & 376180 & 2540 & 367550 & 2580 & 360430 & 2640 & 354660 & 2640 & 351530 \\
\hline L1_W2 & 2480 & 377050 & 2520 & 368580 & 2540 & 361910 & 2580 & 354960 & 2600 & 351600 \\
\hline L1_W3 & 2420 & 378120 & 2460 & 368990 & 2500 & 362320 & 2540 & 355740 & 2600 & 352690 \\
\hline
\end{tabular}

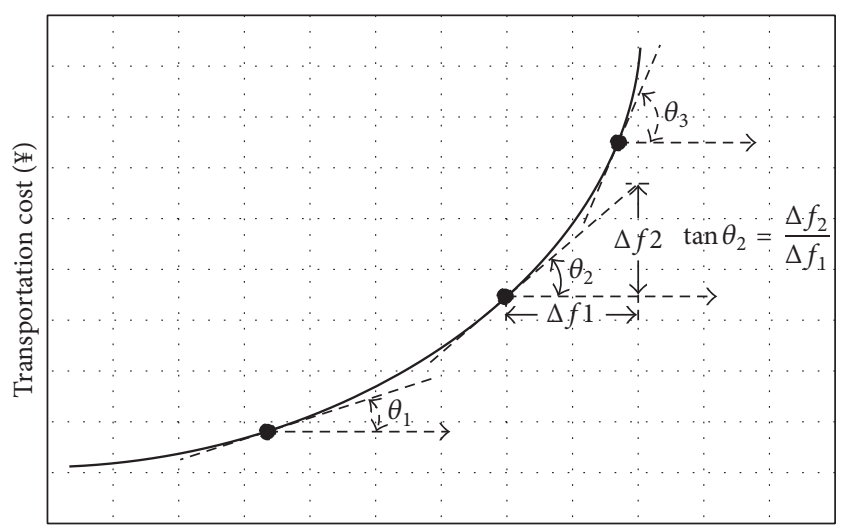

Sharing space (TEUs)

FIGURE 6: Relationships between yard space and operation cost.

the container terminal yard storage is extremely scarce that could infect yard operation, the operators should create more storage space and the space-utilizing oriented strategy may be adopted; that is, $a$ should take a bigger value; otherwise the cost saving should be the primary selection. It is worth noting that the marginal cost of yard sharing space $(\tan \theta)$ grows nonlinearly with the increase of coefficient $a$.

5.3. Yard Crane Resource Analysis. In this section, the effects of total YCs on yard storage space utilization and yard operation cost are tested. We changed the number of YCs in

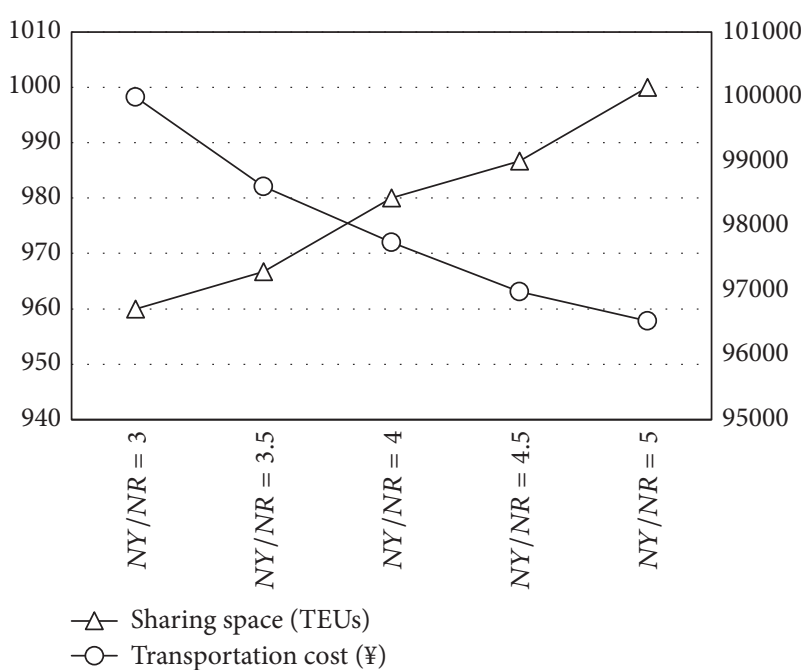

FIGURE 7: Yard crane influence of small-scale experiments.

the yard, and the other parameters are unchanged. For this group of experiments, consider the yard sharing space and yard operation cost separately, so the coefficient $a$ is equal to 1 and 0 , respectively, in the calculation of yard sharing space and yard operation cost. The detailed results are shown in Table 4 .

Figures 7, 8, and 9 show the effects of YCs on yard sharing space and yard operation cost intuitively. From these figures, 
TABLE 5: Results of instances with different subblock volume.

\begin{tabular}{|c|c|c|c|c|c|c|c|c|}
\hline \multirow[b]{2}{*}{ Instances } & \multicolumn{2}{|c|}{$N S / N B=3$} & \multicolumn{2}{|c|}{$N S / N B=4$} & \multicolumn{2}{|c|}{$N S / N B=5$} & \multicolumn{2}{|c|}{$N S / N B=6$} \\
\hline & $\begin{array}{c}f 1 \\
\text { (TEUs) }\end{array}$ & $\begin{array}{l}f 2 \\
(¥)\end{array}$ & $\begin{array}{c}f 1 \\
\text { (TEUs) }\end{array}$ & $\begin{array}{l}f 2 \\
(¥)\end{array}$ & $\begin{array}{c}f 1 \\
\text { (TEUs) }\end{array}$ & $\begin{array}{l}f 2 \\
(¥)\end{array}$ & $\begin{array}{c}f 1 \\
\text { (TEUs) }\end{array}$ & $\begin{array}{l}f 2 \\
(¥)\end{array}$ \\
\hline S2_W1 & 756 & 106550 & 880 & 99990 & 960 & 95680 & - & - \\
\hline S2_W2 & 756 & 106550 & 880 & 99990 & 960 & 96280 & - & - \\
\hline S2_W3 & 756 & 106550 & 880 & 99990 & 960 & 99200 & - & - \\
\hline M2_W1 & 1404 & 231680 & 1680 & 221760 & 1888 & 217440 & 1950 & 210870 \\
\hline M2_W2 & 1404 & 231760 & 1600 & 221950 & 1856 & 215210 & - & - \\
\hline M2_W3 & 1350 & 235930 & 1560 & 222140 & 1824 & 218130 & - & - \\
\hline L2_W1 & 2214 & 394550 & 2480 & 376180 & 2720 & 366960 & 2938 & 359620 \\
\hline L2_W2 & 2214 & 396640 & 2480 & 377050 & 2688 & 371090 & - & - \\
\hline L2_W3 & 2160 & 398150 & 2400 & 378120 & 2656 & 373210 & - & - \\
\hline
\end{tabular}

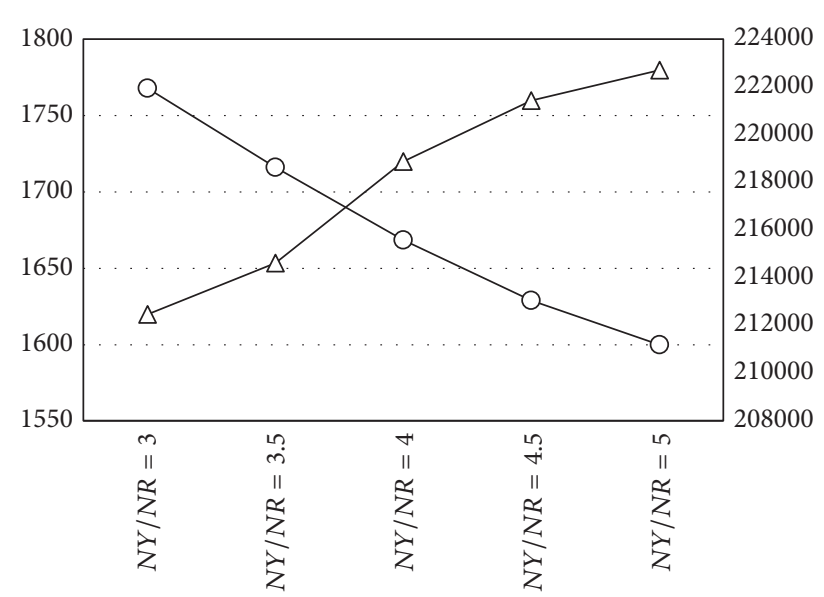

$\triangle$ Sharing space (TEUs)

-O- Transportation cost (¥)

Figure 8: Yard crane influence of medium-scale experiments.

we can find that the sharing space gradually becomes bigger with the average YCs number in each zone increasing, but the yard operation cost has an opposite situation.

For the increasing of yard sharing space, the main reason could be that the added YCs relieved the YC loading point constraint and then created more flexible service lines pairings among subblocks, but this effect is slight, only about $4 \%$.

However, generally speaking, the increase of YCs should decrease the yard operation cost considerably because it can avoid yard crane interzone movement as far as possible. But these results shown in the figures could not express this phenomenon obviously; there is still only $6 \%$ cost decrease. A significant cause of this phenomenon is that the operation cost we considered is on the situation that the objective function is cost-saving pattern (the coefficient $\alpha$ equal to 0 ), so the yard operation cost we compared has been optimized. It means that the amount of YCs interzone movements has been decreased to an optimal level, and this phenomenon could be directly identified by Table 3 in Section 5.1.

5.4. Subblock Volume Analysis. The authors are also interested in how the volume of subblock infects the yard space

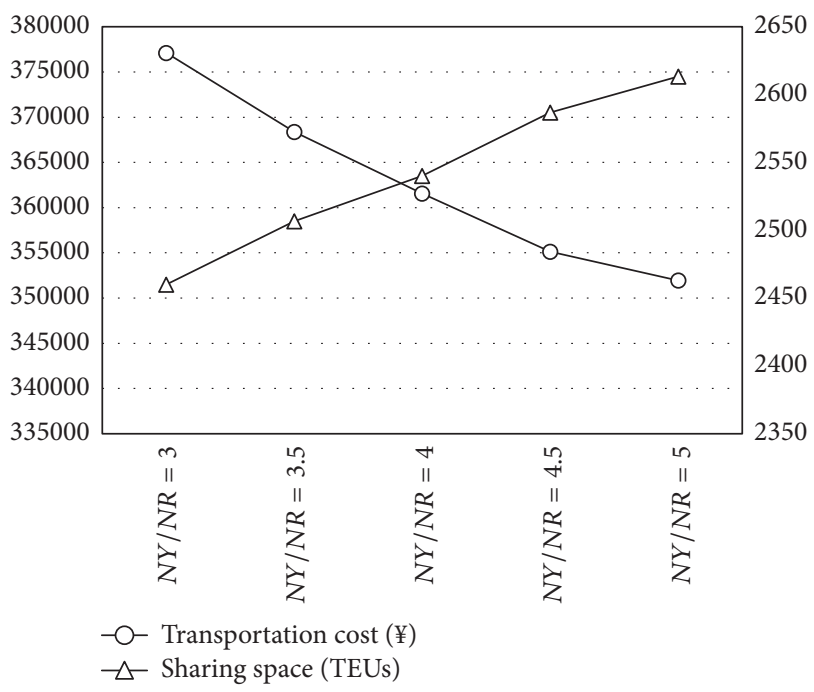

FIGURE 9: Yard crane influence of large-scale experiments.

utilization and yard operation cost. In this subsection, the number of subblocks in each block is divided into $3,4,5$, and 6; thus the volume of each subblock is equal to 270, 200, 160 , and 130 TEUs, respectively, and the other parameters are unchanged. Similar to Section 5.3, the coefficient $a$ is equal to 1 and 0 , respectively, in the calculation of yard sharing space and yard operation cost. The detailed results are shown in Table 5.

As showed in Figures 10, 11, and 12, with the volume of subblock decreasing and the subblocks in the yard block increasing gradually, that the pairing of service lines became more flexible. Consequently, the space sharing opportunity increased and the yard operation cost decreased as well. However, with the decreasing of yard subblocks volume, the yard crane service range is limited, and such trends will limit the increase of the yard crane resource demand in the yard. When the number of subblocks in the block reaches a certain value, the whole container terminal yard area cannot run normally. Accordingly, the volume of yard subblock also plays an important role in yard management. If the value is too large, the sharing space opportunity will decrease and operation cost will increase. However, if the value is too small, the whole system operation pattern will be broken up. 


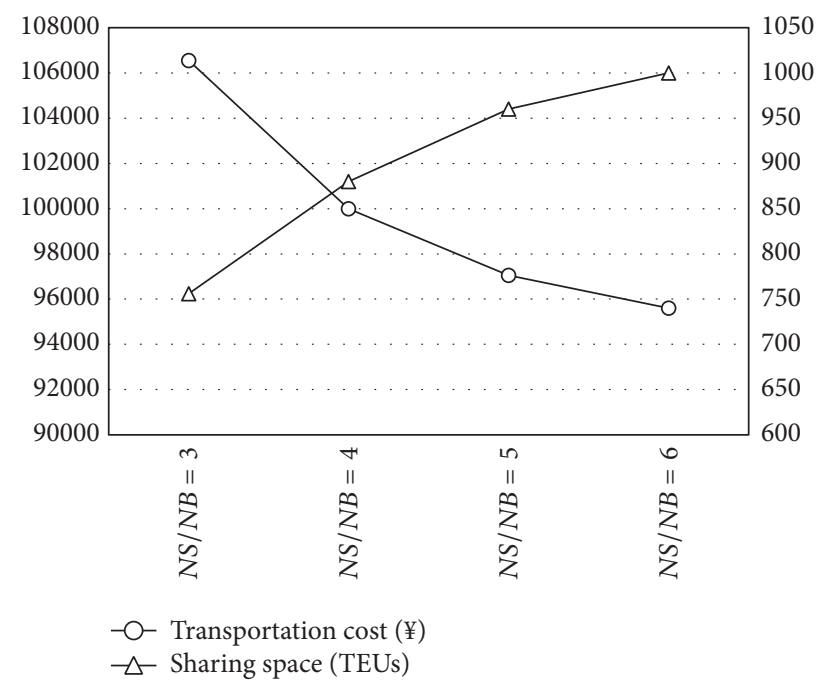

FIGURE 10: Yard subblock size influence of small-scale experiments.

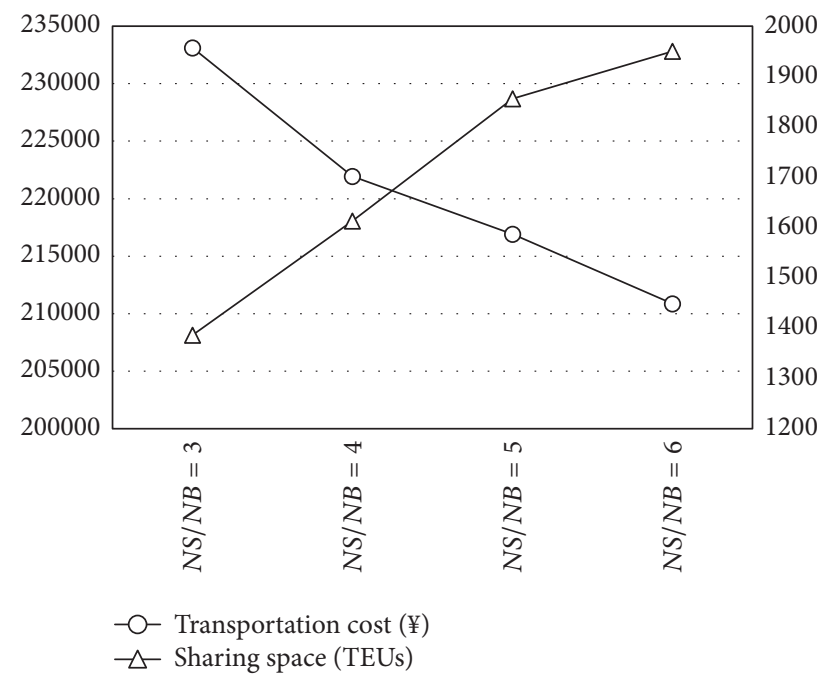

FIGURE 11: Yard subblock size influence of medium-scale experiments.

\section{Conclusions}

Motivated by the requirement to relieve the operation dilemma for resource-limited container terminal, this paper addressed the integrated yard space allocation and yard crane deployment problem. Two corresponding counterstrategies are introduced, and then an integrated mathematical model is formulated to solve the problem. Numerical experiments verified the correctness and accuracy of the proposed model. This study found that space sharing strategy can increase yard space utilization, and yard crane interzone movement strategy can effectively relieve the shortage of YCs. In addition, an interesting phenomenon is discovered that there exists a trade-off between yard space utilization and yard operation cost, and the volume of yard subblock also plays a significant role in container port yard management.

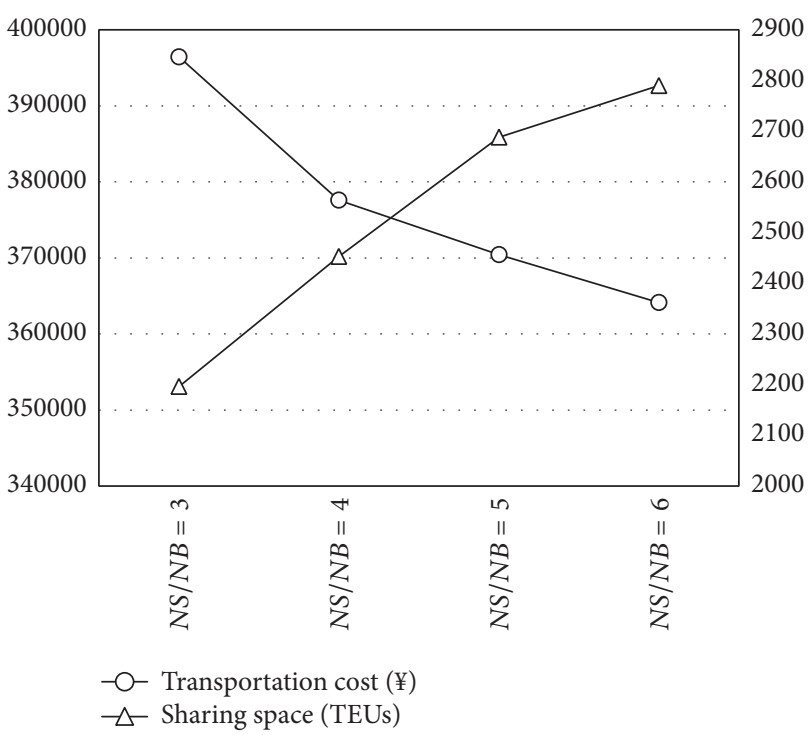

FIGURE 12: Yard subblock size influence of large-scale experiments.

This research can be extended in many relative areas. In this paper, the service line working windows and yard crane efficiency are determined. However, these parameters may fluctuate with the factors associated with natural factors and the equipment operators in reality. Therefore, the application of uncertainty factors in the integrated management problem is a valuable research direction in the future.

\section{Competing Interests}

The authors declare that they have no competing interests.

\section{Authors' Contributions}

All authors contributed equally and significantly to writing this article.

\section{Acknowledgments}

This work is sponsored by National Natural Science Foundation of China (71602114), "Chenguang Program" supported by Shanghai Education Development Foundation and Shanghai Municipal Education Commission (14CG48), Shanghai Sailing Program (14YF1411200), Doctoral Fund of the Ministry of Education (20133121110001), Shanghai Municipal Education Commission Project (14YZ112), Shanghai Science \& Technology Committee Research Project (15590501700), Shanghai Maritime University Doctoral Innovation Fund Project (2015ycx063), and Shanghai Maritime University Doctoral Excellent Thesis Training Program (2015BXLP006).

\section{References}

[1] D. Chang, Z. H. Jiang, W. Yan, and J. He, "Integrating berth allocation and quay crane assignments," Transportation Research 
Part E: Logistics \& Transportation Review, vol. 46, no. 6, pp. 975990, 2010.

[2] J. L. He, D. F. Chang, W. J. Mi, and W. Yan, "A hybrid parallel genetic algorithm for yard crane scheduling," Transportation Research Part E: Logistics and Transportation Review, vol. 46, no. 1, pp. 136-155, 2010.

[3] J. G. Jin, D. Lee, and J. X. Cao, "Storage yard management in maritime container terminals," Transportation Science, 2014.

[4] C.-H. Chen and W. Yan, "Engineering informatics in port operations and logistics," Advanced Engineering Informatics, vol. 25, no. 3, pp. 401-402, 2011.

[5] C.-H. Chen, L. P. Khoo, Y. T. Chong, and X. F. Yin, "Knowledge discovery using genetic algorithm for maritime situational awareness," Expert Systems with Applications, vol. 41, no. 6, pp. 2742-2753, 2014.

[6] J. He, Y. Huang, and D. Chang, "Simulation-based heuristic method for container supply chain network optimization," Advanced Engineering Informatics, vol. 29, no. 3, pp. 339-354, 2015.

[7] I. F. A. Vis and R. De Koster, "Transshipment of containers at a container terminal: an overview," European Journal of Operational Research, vol. 147, no. 1, pp. 1-16, 2003.

[8] D. Steenken, S. Voß, and R. Stahlbock, "Container terminal operation and operations research-a classification and literature review," OR Spectrum, vol. 26, no. 1, pp. 3-49, 2004.

[9] R. Stahlbock and S. Voß, "Operations research at container terminals: a literature update," Operations Research-Spektrum, vol. 30, no. 1, pp. 1-52, 2008.

[10] X. Jiang, L. H. Lee, E. P. Chew, Y. Han, and K. C. Tan, "A container yard storage strategy for improving land utilization and operation efficiency in a transshipment hub port," European Journal of Operational Research, vol. 221, no. 1, pp. 64-73, 2012.

[11] L. H. Lee, E. P. Chew, K. C. Tan, and Y. Han, "An optimization model for storage yard management in transshipment hubs," $O R$ Spectrum, vol. 28, no. 4, pp. 539-561, 2006.

[12] Y. Han, L. H. Lee, E. P. Chew, and K. Tan, "A yard storage strategy for minimizing traffic congestion in a marine container transshipment hub," OR Spectrum. Quantitative Approaches in Management, vol. 30, no. 4, pp. 697-720, 2008.

[13] X. Jiang, E. P. Chew, L. H. Lee, and K. C. Tan, "Flexible spacesharing strategy for storage yard management in a transshipment hub port," OR Spectrum, vol. 35, no. 2, pp. 417-439, 2013.

[14] L. Zhen, "Container yard template planning under uncertain maritime market," Transportation Research Part E: Logistics and Transportation Review, vol. 69, pp. 199-217, 2014.

[15] C. Zhang, Y.-W. Wan, J. Liu, and R. J. Linn, "Dynamic crane deployment in container storage yards," Transportation Research Part B: Methodological, vol. 36, no. 6, pp. 537-555, 2002.

[16] R. K. Chung, C.-L. Li, and W. Lin, "Interblock crane deployment in container terminals," Transportation Science, vol. 36, no. 1, pp. 79-93, 2002.

[17] R. Linn, J.-Y. Liu, Y.-W. Wan, C. Q. Zhang, and K. G. Murty, "Rubber tired gantry crane deployment for container yard operation," Computers \& Industrial Engineering, vol. 45, no. 3, pp. 429-442, 2003.

[18] Z. Cao, D.-H. Lee, and Q. Meng, "Deployment strategies of double-rail-mounted gantry crane systems for loading outbound containers in container terminals," International Journal of Production Economics, vol. 115, no. 1, pp. 221-228, 2008.
[19] K. H. Kim and H. B. Kim, "The optimal sizing of the storage space and handling facilities for import containers," Transportation Research Part B: Methodological, vol. 36, no. 9, pp. 821-835, 2002.

[20] D.-H. Lee, J. G. Jin, and J. H. Chen, "Integrated bay allocation and yard crane scheduling problem for transshipment containers," Transportation Research Record, vol. 2222, no. 8, pp. 63-71, 2011.

[21] S. H. Won, X. Zhang, and K. H. Kim, "Workload-based yardplanning system in container terminals," Journal of Intelligent Manufacturing, vol. 23, no. 6, pp. 2193-2206, 2012. 

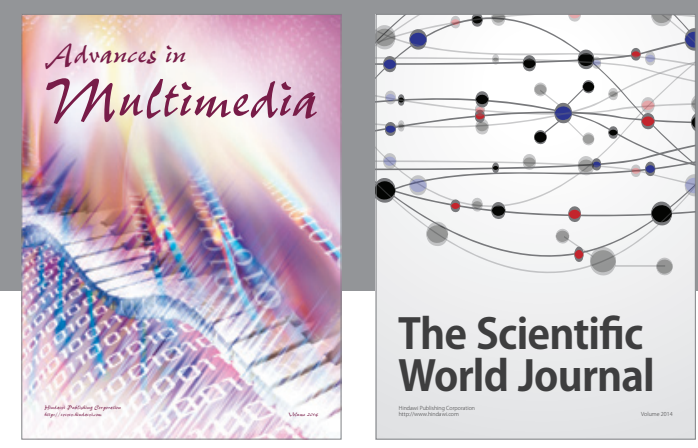

The Scientific World Journal
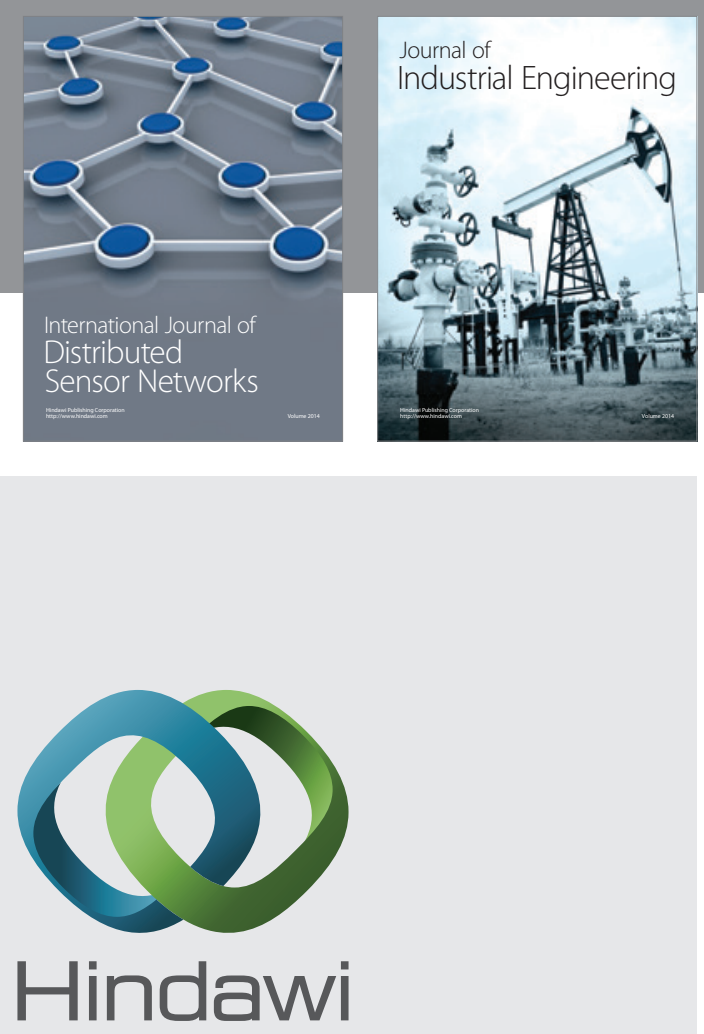

Submit your manuscripts at

http://www.hindawi.com

\section{Computer Networks} and Communications
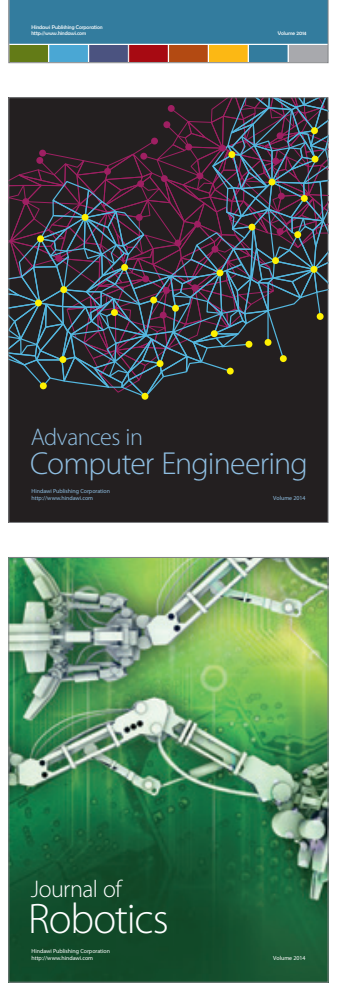
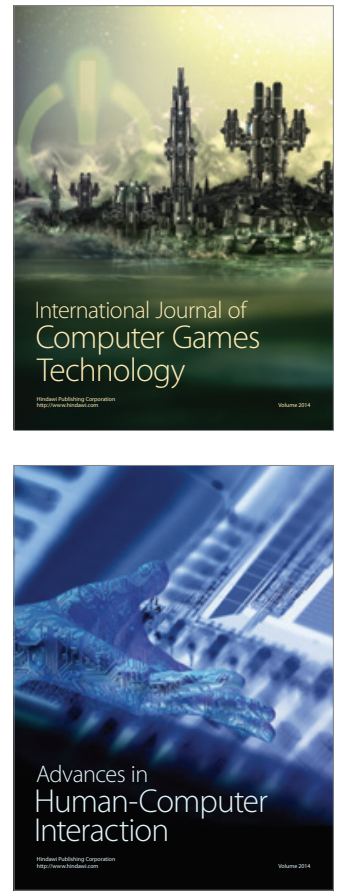
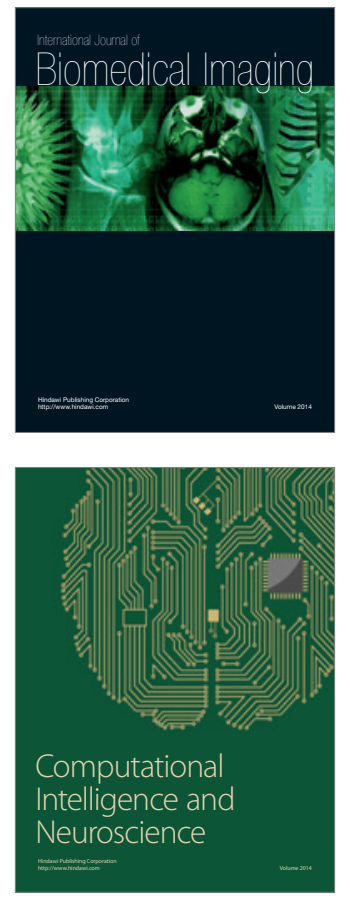
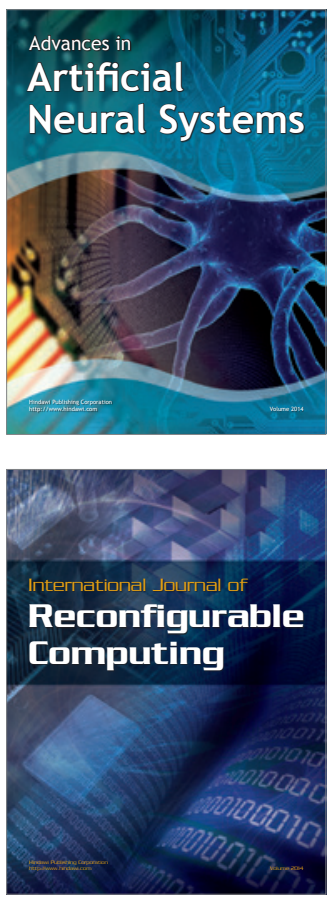
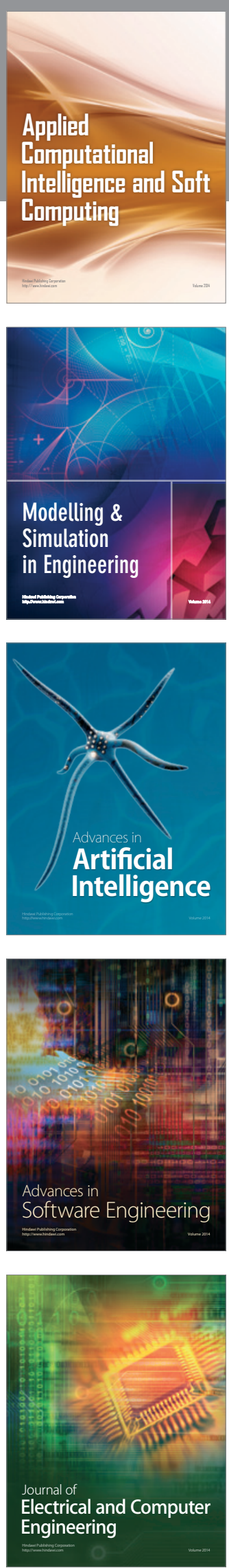